\title{
Future Interventional Radiologists and Where to Find Them- Insights from Five UK Interventional Radiology Symposia for Junior Doctors and Medical Students
}

\author{
Yiwang Xu ${ }^{1,2} \cdot$ Anum Pervez $^{3,4} \cdot$ Iakovos Theodoulou $^{5} \cdot \operatorname{Jim}$ Zhong $^{6}$ •

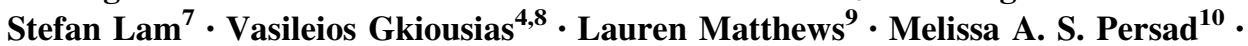 \\ Gregory C. Makris ${ }^{5,11}$ (D)
}

Received: 21 May 2020/Accepted: 16 September 2020/Published online: 9 October 2020

(C) Springer Science+Business Media, LLC, part of Springer Nature and the Cardiovascular and Interventional Radiological Society of Europe (CIRSE) 2020

\begin{abstract}
Background The interventional radiology (IR) trainee recruitment in the UK is lagging behind the pace of service expansion and is potentially hindered by underrepresented undergraduate curricula. Understanding the contributing factors that encourage junior doctors and medical students to consider an IR career will help the IR community to better focus the efforts on recruiting and nurturing the next generation.

Methods Anonymised questionnaires on undergraduate and postgraduate IR exposure were distributed to attendees of five UK IR symposia between 2019 and 2020.

Results 220 responses were received from 103 (47\%) junior doctors and $117(53 \%)$ medical students. Prior IR exposure strongly correlates with individuals' positive views towards an IR career (Pearson's $R=0.40, p<$
\end{abstract}

Electronic supplementary material The online version of this article (https://doi.org/10.1007/s00270-020-02655-7) contains supplementary material, which is available to authorised users.

\section{Gregory C. Makri}

G.makris09@doctors.org.uk

1 Imaging Department, Imperial College Healthcare NHS Trust, London, UK

2 Department of Radiology, Royal Free London NHS Foundation Trust, London, UK

3 Department of Clinical Radiology, Guy's and St Thomas' NHS Foundation Trust, London, UK

4 Royal Free Undergraduate Centre, University College London Medical School, London, UK

5 Department of Vascular and Interventional Radiology, Guy's and St Thomas' NHS Foundation Trust, London, UK
0.001), with involvement in clinical activities as the most important independent contributor (OR 3.6, 95\% CI $1.21-10.50, p=0.021$ ). Longer time spent in IR (especially as elective modules) and IR-related portfolio-building experiences (such as participating in research, attending conferences and obtaining career guidance) demonstrate strong association with willingness to pursue an IR career for the more motivated ( $p$ values $<0.05$ ). The symposia had overall positive effects on subjective likelihood to pursue an IR career, particularly among junior doctors who face near-term career choices $(p<0.001)$.

Conclusion Our study, focusing on a self-selected cohort, identified contributing factors to individuals' willingness to pursue an IR career. Symposia have additional recruitment effects in extra-curricular settings. Active engagement with junior doctors and medical students through clinical activities and non-clinical portfolio-related experiences are key to generate informed and motivated candidates for the future of IR.

6 Department of Radiology, Leeds Teaching Hospitals NHS Trust, Leeds, UK

7 Barts and The London School of Medicine and Dentistry, Queen Mary University of London, London, UK

8 Department of Ear, Nose and Throat Surgery, Brighton and Sussex University Hospitals NHS Trust, Brighton, UK

9 Department of Emergency Medicine, North Middlesex University Hospital NHS Trust, London, UK

10 Department of Vascular Surgery, Royal Free London NHS Foundation Trust, London, UK

11 Alfa Institute of Biomedical Sciences, Neapoleos 9, Marousi, Athens, Greece 
Keywords Interventional radiology $\cdot$ Workforce . Recruitment $\cdot$ Symposia $\cdot$ Undergraduate curricula

\section{Introduction}

Interventional radiology (IR) has gained increasing recognition in modern hospital medicine, paralleled by growing demands and rapid expansion in both emergency and elective patient care. However, there is a significant shortage of interventional radiologists (IRs) in the UK. Forty-five per cent of the services in England are not able to provide out-of-hours access to IR due to a $36 \%$ (or 379 ) shortfall of IRs. A shortage of suitably trained candidates has been identified as one of the major contributors to this workforce crisis [1].

The current IR training in the UK consists of two stages over a total of six years (Fig. 1), with three years in core training and three years in IR specialist training. The core training programme is a common pathway for both diagnostic and interventional radiology candidates. Postgraduate doctors can apply to enter radiology core training after they finish their two-year foundation training programme, or at any later stages (e.g. during core or high specialty training in other specialties, or at equivalent nontraining grades). Only following successful completion of core radiology training, trainees can then undertake dedicated IR specialty training for another three years. A Certificate of Completion of Training (CCT) is required for the individual to be added to the specialty registry on completion of training, whereas the European Board of Interventional Radiology (EBIR) accreditation is currently not mandatory. While this pathway provides a solid ground in diagnostic radiology, the IR recruitment process is relatively disjointed.

Recent studies have shown that IR is underrepresented in medical school's curricula and medical student exposure is generally inadequate in the UK, as well as the rest of Europe [2-5]. It has been suggested that the lack of exposure and knowledge demotivate medical students from pursuing a career in IR [6]. The introduction of IR curricula from the Cardiovascular and Interventional Radiological Society of Europe (CIRSE) and the British Society of Radiology (BSIR) for medical students [7, 8] is intended to have a positive impact at the undergraduate level. A variety of outreach schemes run by professional organisations continues to engage undergraduate students and postgraduate doctors, including those organised by CIRSE and BSIR.

Additionally, one-day symposia, a cost-effective recruitment strategy used by IR and many other specialties [9], have rapidly gained popularity in the UK in response to the increasing demand of supplemental IR knowledge and career insights in the extra-curricular domain. There was a record-breaking total of five IR symposia held between September 2019 and February 2020 (Table 1) and a few more scheduled but disrupted by the COVID-19 pandemic. While some were IR specific, some events also included educational diagnostic radiology topics to increase their audience base. Most events featured inspirational talks, career insights, practical skills workshops and networking opportunities. The target audiences were mainly junior doctors not currently in radiology training and medical students; radiology core trainees were also welcomed.

The attendees of these symposia form a unique cohort with pre-established interests in IR. This presents an opportunity to explore the contributing factors during their undergraduate and postgraduate training that encouraged them to consider becoming IRs. This study will supplement the current knowledge primarily drawn from blanket surveys on general medical student populations [2,3]. It will also help the IR community to better focus the efforts on recruiting and nurturing the next generation of IRs.

\section{Methods}

Anonymised questionnaires were distributed either in paper or digital formats to attendees at the five events listed in Table 1 . The questionnaire includes 15 questions covering basic demographics, qualitative and quantitative

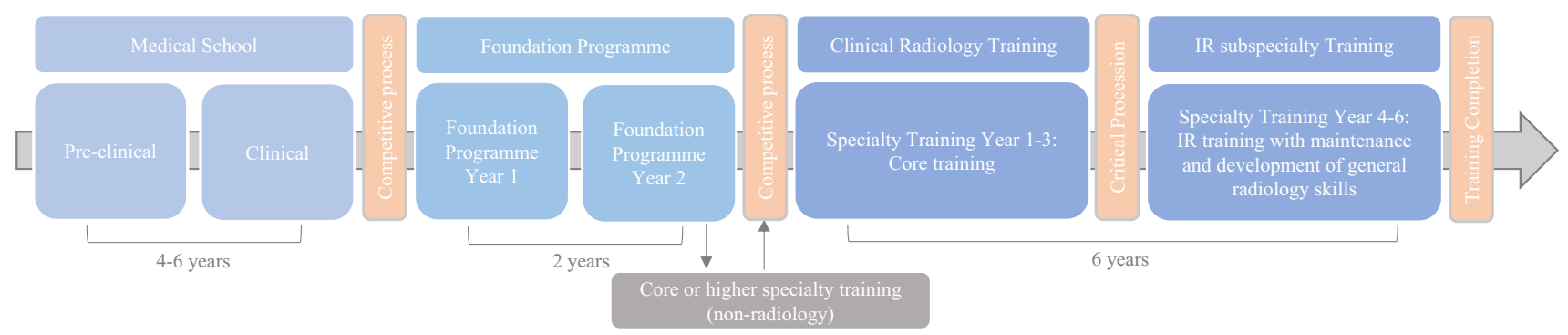

Fig. 1 Current interventional radiology training pathway in the UK 
Table 1 Overview of the IR-related outreach events for junior doctors and medical students during the 2019-2020 academic year before the COVID-19 outbreak in the UK

\begin{tabular}{|c|c|c|c|c|c|}
\hline Event & Date & Location & Organiser & Capacity & IR-specific \\
\hline $\begin{array}{l}\text { National Interventional Radiology } \\
\text { Symposium (NIRS) }\end{array}$ & September 2019 & London & $\begin{array}{l}\text { Radiology trainees } \\
\text { (not-for-profit) }\end{array}$ & 80 & Yes \\
\hline $\begin{array}{l}\text { King's College London National } \\
\text { Interventional Radiology } \\
\text { Conference (KiRCo) }\end{array}$ & October 2019 & London & Student society & 60 & Yes \\
\hline${\text { BSIR Trainee Day }(B S I R T)^{a}}^{a}$ & November 2019 & Manchester & BSIR Trainee Committee & 100 & Yes \\
\hline $\begin{array}{l}\text { Bart's National Undergraduate } \\
\text { Radiology Conference (BURC) }\end{array}$ & January 2020 & London & Student society & 40 & $\begin{array}{l}\text { With both interventional and } \\
\text { diagnostic components }\end{array}$ \\
\hline $\begin{array}{l}\text { Yorkshire Imaging and Interventional } \\
\text { Radiology Symposium (YiiR) }\end{array}$ & February 2020 & Leeds & Student society & 70 & Yes \\
\hline
\end{tabular}

${ }^{a}$ BSIRT sessions are run parallel to the BSIR annual meeting programme

assessment on prior IR exposure and subjective opinions (Supplement 1). Individuals who attended multiple events were surveyed once. For the Bart's National Undergraduate Radiology Conference (BURC), only responses from those who specifically expressed interest in the IR aspect of the event were collected.

The subjects were categorised according to their stage of training. In addition, foundation trainees, nonradiology core and high specialty trainees (or equivalent) and radiology core trainees were grouped together as the 'junior doctors' subgroup, as opposed to medical students who may yet to have more IR exposure at medical schools. Subjects in the 'junior doctors' group have exposures beyond the undergraduate level of IR experience and are more likely to face near-term career choices.

Categorical variables were compared using Chi-square tests or Fisher's exact test when appropriate. Numeric variables were compared using independent or paired $T$ test as appropriate. The correlations between discrete numeric variables were analysed using Pearson $R$ test. Multivariate binary logistic regression was performed on the junior doctors' group. $P$ values $<0.05$ were considered statistically significant. Statistical analyses were carried out with SPSS version 25 .

\section{Results}

A total of 220 valid responses were obtained from similar numbers of male and female subjects (Table 2). The overall response rate was at $90 \%$. The proportion of audiences' stage of training varied by event, reflecting each event's target audience group. Among those that responded to the survey, $82 \%(N=181)$ first learnt about IR during medical school; however, $18 \%(N=39)$ only came across IR during their postgraduate training. The vast majority $(95 \%$, $N=163$ ) became interested in IR by the Foundation stage of training, a large proportion $(57 \%, N=125)$ of which were during their clinical undergraduate training.

With regard to prior IR experiences, $38 \%(N=84)$ considered themselves having had more exposure than their peers and $50 \%(N=109)$ at similar levels, and their subjective assessments strongly correlate (Pearson's $R=0.49, p<0.001$ ) with their objective exposure (in broad categories of undergraduate experience, clinical involvement, and portfolio and career preparation; data not shown). Overall, $81 \%(N=177)$ did not consider the undergraduate curricular IR exposure sufficient, while $16 \%$ $(N=34)$ were unsure. Eighty-four per cent $(N=184)$ were not aware of any published IR undergraduate curricula. Moreover, $78 \%(N=172)$ were unsure or did not feel there were sufficient extra-curricular IR opportunities either. Among them, 35\% $(N=61)$ and $74 \%(N=127)$ have not engaged with BSIR or CIRSE, respectively. In total, $85 \%$ $(N=186)$ were supportive of creating a portal website dedicated to providing information on IR-related events and resources for junior doctors and medical students.

Prior to the events, $61 \%(N=134)$ of subjects felt 'likely' or 'very likely' to pursue a career in IR, while $31 \%$ $(N=69)$ felt 'neutral', which is positively correlated with objective exposures (Pearson's $R=0.40, P<0.001$ ). With $97 \%(N=213)$ good ratings, the symposia had a positive impact on recruitment (Fig. 2) by having individuals remain as willing or become increasingly willing to consider a career in IR (mean post-event Likert scale score $3.93 \pm 0.83$ vs. pre-event score $3.78 \pm 0.87, p<0.01$ ). The effects were equally marked among the postgraduate doctors and medical students (mean post-event Likert scale 
Table 2 Baseline characteristics of the survey responders from the five UK events

\begin{tabular}{|c|c|c|c|c|c|c|}
\hline & Overall (\%) & BSIRT $(\%)$ & NIRS (\%) & KiRCo (\%) & BURC (\%) & YiiR (\%) \\
\hline Responses & 220 & $31(14)$ & $70(32)$ & $48(22)$ & $28(13)$ & $43(20)$ \\
\hline Return rates & $90 \%$ & $\mathrm{~N} / \mathrm{A}^{\mathrm{a}}$ & $99 \%$ & $94 \%$ & $100 \%$ & $70 \%$ \\
\hline Male gender & $122(55)$ & $18(58)$ & $40(57)$ & $26(54)$ & $11(39)$ & $27(63)$ \\
\hline UK medical graduate & $208(95)$ & $30(97)$ & $65(93)$ & $46(96)$ & $28(100)$ & $39(91)$ \\
\hline \multicolumn{7}{|l|}{ Stage of training } \\
\hline Preclinical student & $27(12)$ & $0(0)$ & $6(8)$ & $9(19)$ & $8(29)$ & $4(9)$ \\
\hline Clinical student & $90(41)$ & $7(23)$ & $14(20)$ & $24(50)$ & $18(64)$ & $27(63)$ \\
\hline Foundation trainee & $61(28)$ & $10(32)$ & $35(50)$ & $5(10)$ & $2(7)$ & $9(21)$ \\
\hline Core trainee or equivalent (nonradiology) & $30(14)$ & $7(23)$ & $11(16)$ & $10(21)$ & $0(0)$ & $2(5)$ \\
\hline High specialty trainee (nonradiology) & $1(0)$ & $1(3)$ & $0(0)$ & $0(0)$ & $0(0)$ & $0(0)$ \\
\hline Radiology core trainee & $11(5)$ & $6(19)$ & $4(6)$ & $0(0)$ & $0(0)$ & $1(2)$ \\
\hline \multicolumn{7}{|l|}{ First heard IR } \\
\hline Preclinical student & $56(25)$ & $2(6)$ & $20(29)$ & $12(25)$ & $17(61)$ & $5(12)$ \\
\hline Clinical student & $125(57)$ & $19(62)$ & $35(50)$ & $29(61)$ & $9(32)$ & $33(77)$ \\
\hline Foundation trainee & $33(15)$ & $8(26)$ & $15(21)$ & $5(10)$ & $2(7)$ & $3(7)$ \\
\hline Core trainee or equivalent (nonradiology) & $6(3)$ & $2(6)$ & $0(0)$ & $2(4)$ & $0(0)$ & $2(4)$ \\
\hline \multicolumn{7}{|l|}{ First became interested in IR } \\
\hline Preclinical student & 37 (17) & $2(6)$ & $11(16)$ & $9(19)$ & $3(11)$ & $3(7)$ \\
\hline Clinical student & $126(57)$ & $19(62)$ & $33(47)$ & $28(58)$ & $14(50)$ & $32(74)$ \\
\hline Foundation trainee & $47(21)$ & $7(23)$ & $24(35)$ & $9(19)$ & $5(19)$ & $5(12)$ \\
\hline Core trainee or equivalent (nonradiology) & $8(4)$ & $2(6)$ & $1(1)$ & $2(4)$ & $3(11)$ & $3(7)$ \\
\hline High specialty trainee (nonradiology) & $1(0)$ & 0 & $1(1)$ & $0(0)$ & $0(0)$ & $0(0)$ \\
\hline Radiology core trainee & $1(0)$ & $1(3)$ & $0(0)$ & $0(0)$ & $0(0)$ & $0(0)$ \\
\hline \multicolumn{7}{|c|}{ Pre-event subjective likelihood to pursue IR as career } \\
\hline Very likely & $46(21)$ & $13(42)$ & $14(20)$ & $10(21)$ & $4(14)$ & $5(12)$ \\
\hline Likely & $89(40)$ & $15(48)$ & $33(47)$ & $20(42)$ & $7(25)$ & $14(32)$ \\
\hline Neutral & $69(31)$ & $3(10)$ & $19(27)$ & $14(29)$ & $12(43)$ & $21(49)$ \\
\hline Unlikely & $15(7)$ & $0(0)$ & $4(6)$ & $3(6)$ & $5(18)$ & $3(7)$ \\
\hline Very unlikely & $1(1)$ & $0(0)$ & $0(0)$ & $1(2)$ & $0(0)$ & $0(0)$ \\
\hline \multicolumn{7}{|c|}{ Pre-event self-assessed exposure to IR comparing to peers } \\
\hline A lot more & $28(13)$ & $10(32)$ & $9(13)$ & $3(6)$ & $2(7)$ & $4(9)$ \\
\hline More & $56(25)$ & $12(39)$ & $19(27)$ & $13(27)$ & $4(14)$ & $8(19)$ \\
\hline Similar & $109(50)$ & $7(23)$ & $32(46)$ & $24(50)$ & $19(68)$ & $27(63)$ \\
\hline Less & $22(10)$ & $1(3)$ & $8(11)$ & $7(15)$ & $2(7)$ & $4(9)$ \\
\hline Much less & $5(2)$ & $1(3)$ & $2(3)$ & $1(2)$ & $1(4)$ & $0(0)$ \\
\hline
\end{tabular}

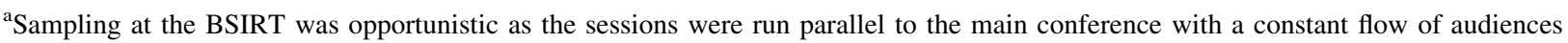
BSIRT British Society of Radiologists Trainee Day; NIRS National Interventional Radiology Symposium; KiRCo King's College London National Interventional Radiology Conference; BURC Bart's National Undergraduate Radiology Conference; and YiiR Yorkshire Imaging and Interventional Radiology Symposium

score increases $0.14 \pm 0.53$ vs. $0.16 \pm 0.46, p=0.68)$. Of note, the symposia had particularly pronounced effects for female attendees compared to male attendees (mean postevent Likert scale score increase $0.21 \pm 0.55$ vs. $0.10 \pm 0.44, p=0.01$ ).

In the 'junior doctors' group, the correlations between subjective and objective assessments of exposure (Pearson's $R=0.44, p<0.001)$ and between exposure and likelihood to pursue an IR career (Pearson's $R=0.35$, $p<0.001)$ remain strongly positive. Their prior IR exposure was divided into several categories as shown in Table 3. The number of days spent on IR-related learning during medical school, including various formats of IR education, e.g. lectures, tutorials, placements and studentselected component/elective modules, is reflective of the quantity of undergraduate curricular experience (Fig. 3). 


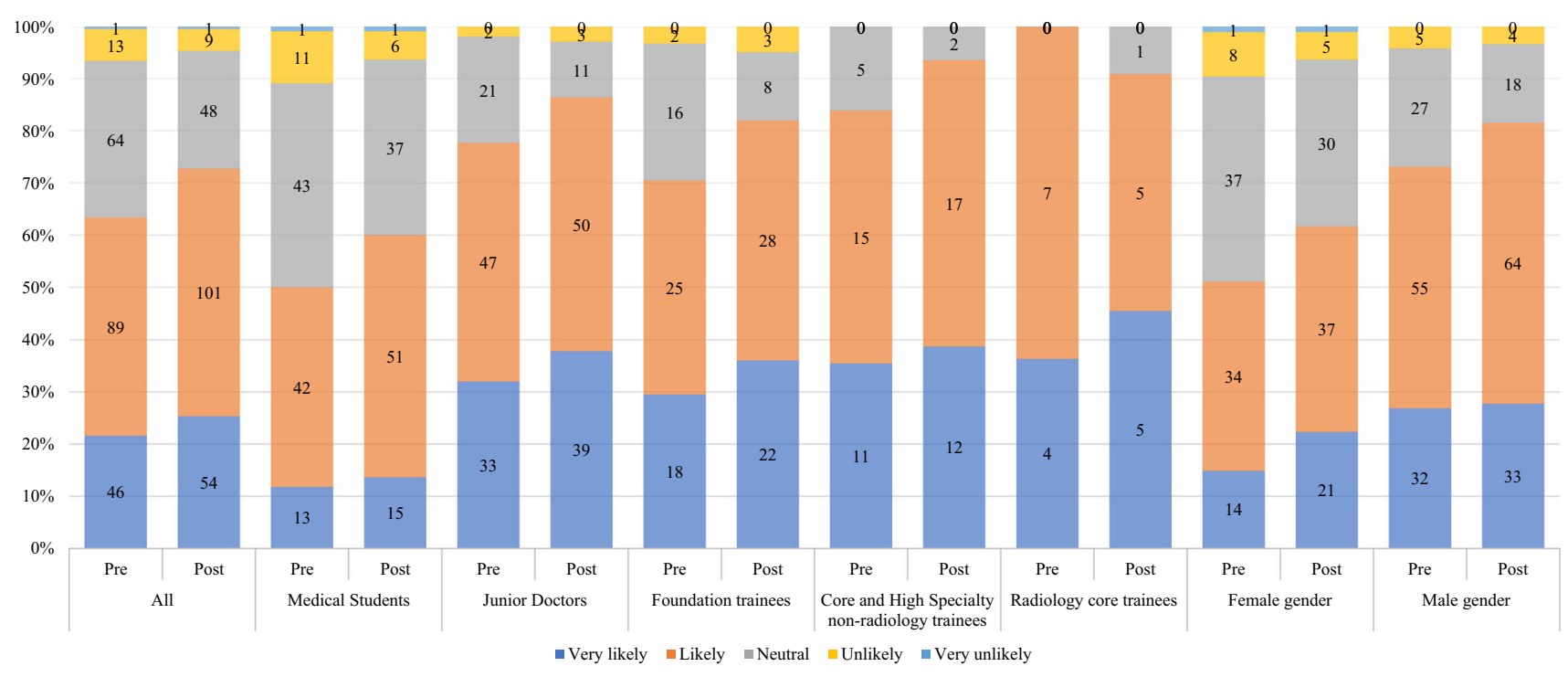

Fig. 2 Pre- and Post-event subjective likelihood to pursue IR career

There were only nine responses to 'postgraduate teaching on IR', and this was therefore excluded from further analysis, as teaching for postgraduate trainees tends to be heterogeneous and firm-focused. Univariate analysis showed that the subjective likelihood of junior doctors to choose IR was significantly positively associated with IRrelated learning during medical school, clinical involvement, and portfolio and career preparations. Other factors such as gender, an early interest in IR since medical school and membership/junior committee roles with professional organisations do not demonstrate statistically significant associations. Multivariate logistic regression analysis further shows clinical involvement is the primary independent contributing factor to a subject's likelihood to pursue an IR career. Exposure to clinical activities makes it 3.6 times more likely [95\% confidence interval 1.21-10.50] for a postgraduate doctor to feel positive about pursuing an IR career.

\section{Discussion}

In our study, we had high response rates from attendees of five IR-related symposia in the UK, which helped to form a large and unique cohort of junior doctors and medical students with overall good prior exposure to IR and positive views towards an IR career, as opposed to a less exposed general population of junior doctors and medical students.

A strong correlation between IR exposure and an individual's subjective likelihood to pursue an IR career is observed. In particular, involvement in clinical activities such as procedures, interdisciplinary decision-making and outpatient consultations has the most significant contribution. It is also observed that more aspiring individuals spent more time in IR-related learning with an average of 8.4 days, usually not achievable during standard undergraduate rotations. The high number was mainly attributed to a few individuals' exceptional commitment, such as choosing IR for student-selective modules and electives of two to nine weeks. Although portfolio and career preparation experiences remained important for a few subjects, they did not reach statistical significance as an independent factor contributing to the subject's likelihood to pursue an IR career. One potential reason is that IRs' supervision time for non-IR junior doctors and students in nonclinical domains is limited and can therefore be targeted towards only a small number of exceptionally motivated individuals. It should also be noted that gender is not a determinant of individuals' attitude towards an IR career in our cohort, which may be partly due to equality campaigns helping to reshape the IR professional image. Of interest, the symposia had more marked effects on the female attendees' career interest in IR. This finding is corroborated by a previous study on an intensive weekend course from Australasia [10]. In our study, all five events featured female IR speakers or workshop tutors acting as role models. Also, concerns and questions about gender-specific areas may have been addressed informally through interactions during networking sessions. Our survey did not specifically enquire about perceived or experienced barriers for female students and doctors to pursue IR careers, such as fear of radiation exposure in child bearing age [11], and this can be a focus for future studies. 
Table 3 Effects of individual characteristics and experiences on willingness to pursue a career in IR among the 'junior doctor' group ( $N=103)$

\begin{tabular}{|c|c|c|c|c|c|c|c|}
\hline & & \multirow{2}{*}{$\begin{array}{l}\text { 'Very } \\
\text { Likely' } \\
\text { or 'Likely' } \\
N=80 \\
(\% \text { or SD) }\end{array}$} & \multirow{2}{*}{$\begin{array}{l}\text { 'Neutral', } \\
\text { 'Unlikely' } \\
\text { or 'Very } \\
\text { Unlikely' } \\
N=23 \text { (\% } \\
\text { or SD) }\end{array}$} & \multirow[t]{2}{*}{$P$ value } & \multicolumn{3}{|c|}{ Multivariate logistic regression } \\
\hline & & & & & $\begin{array}{l}\text { Odds } \\
\text { ratio } \\
(\mathrm{OR})\end{array}$ & $\begin{array}{l}95 \% \\
\text { confidence } \\
\text { interval }(\mathrm{CI})\end{array}$ & $P$ value \\
\hline Gender & Male/female & $\begin{array}{l}48(60) / 32 \\
(40)\end{array}$ & $\begin{array}{r}13(57) / \\
10(43)\end{array}$ & 0.765 & - & - & - \\
\hline \multirow{2}{*}{$\begin{array}{c}\text { Undergraduate } \\
\text { experiences }\end{array}$} & Became interested in IR during medical school & $38(48)$ & $8(35)$ & 0.280 & - & - & - \\
\hline & $\begin{array}{l}\text { Days in IR-related learning during medical } \\
\text { school }\end{array}$ & $8.4( \pm 15)$ & $\begin{array}{l}2.7 \\
( \pm 6.0)\end{array}$ & $0.009^{*}$ & 1.03 & $0.96-1.10$ & 0.411 \\
\hline $\begin{array}{l}\text { Clinical } \\
\text { involvement }\end{array}$ & $\begin{array}{l}\text { Any of: } \\
\text { Observed or assisted IR procedure } \\
\text { Attended multidisciplinary meetings or } \\
\text { discussions } \\
\text { Shadowed outpatient clinics }\end{array}$ & $64(80)$ & $12(52)$ & $0.007^{*}$ & 3.56 & $1.21-10.50$ & $0.021^{*}$ \\
\hline \multirow[t]{3}{*}{$\begin{array}{l}\text { Portfolio and } \\
\text { career } \\
\text { preparation }\end{array}$} & $\begin{array}{l}\text { Any of: } \\
\text { Undertook IR self-guided study } \\
\text { Attended IR courses } \\
\text { Attended IR conferences }\end{array}$ & $59(74)$ & $12(52)$ & $0.049^{*}$ & 2.38 & $0.81-6.98$ & 0.115 \\
\hline & $\begin{array}{l}\text { Any of: } \\
\text { Participated in IR audits } \\
\text { Participated in IR research } \\
\text { Involved in IR case report }\end{array}$ & $24(31)$ & $2(9)$ & $0.033^{*}$ & 1.88 & $0.34-10.42$ & 0.469 \\
\hline & $\begin{array}{l}\text { Received career advice from IR consultants or } \\
\text { trainees }\end{array}$ & $56(70)$ & $11(48)$ & $0.049^{*}$ & 1.58 & $0.54-4.65$ & 0.408 \\
\hline $\begin{array}{l}\text { Professional } \\
\text { engagement }\end{array}$ & $\begin{array}{l}\text { Had a membership or junior committee role } \\
\text { with IR professional organisations }\end{array}$ & $12(15)$ & $1(4)$ & 0.159 & - & - & - \\
\hline
\end{tabular}

* Statistically significant values

This study again highlights the insufficiency of IR exposure at undergraduate level, in line with existing literature [2, 3, 12, 13]. We have selected a more exposed cohort, compared to the general population of junior doctors and medical students, and yet there are marked differences among individuals in the content, duration and intensity of IR undergraduate education. IR teaching models from modular to integrated designs have been proposed to locally adapt the published undergraduate curricula $[3,6,14,15]$ but more consistent implementation at the national level is still required. Inadequate undergraduate curricula and heterogeneous individual experience are likely contributors to the small proportion who therefore only come across IR during their postgraduate training. However, not having an early interest in IR during medical school does not preclude individuals from pursuing IR from a later stage-junior doctors remain important potential candidates.
Our study also highlights that the current level of extracurricular exposure is insufficient. Considering that these self-selected subjects are exceptionally motivated, the study shows that they are not well informed. One-third and three-quarters have not engaged with BSIR or CIRSE (nor their junior programmes), respectively. Very few are aware of the published IR medical student curricula either. This demonstrates the need for continuous efforts and more innovative approaches to reach out to those potentially impressionable but unaware or less exposed, as well as to provide information and opportunities to those already interested and motivated. Indeed, most attendees expressed interest in a portal website dedicated to IR-related events and resources, which is subsequently realised via the IRJuniors.com website. This nonprofit platform attracted approximately 1800 visits and 800 subscribers between December 2019 and August 2020 (I Mandal, written communication, 27 August 2020). Social media, particularly Twitter, has been shown to effectively generate user 
Fig. 3 Days spent in IR-related learning during medical school versus subjective likelihood to pursue a career in IR among the 'junior doctor' group $(N=103)$

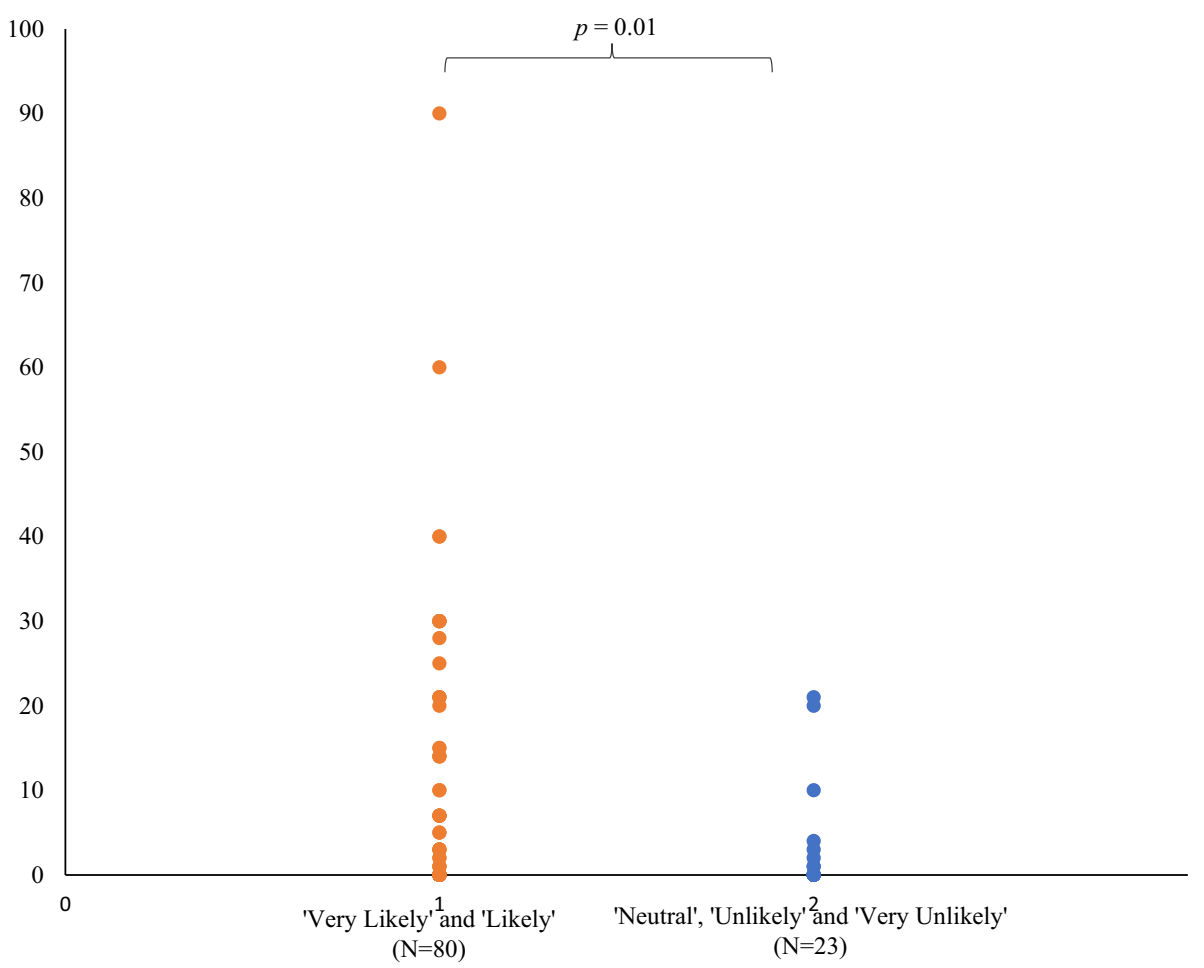

engagement among IRs [16] and can be utilised as an accessible and cost-friendly outreach platform. It can also be a useful tool to widen IR engagement and increase IR awareness among the patients, the general public and IR referrers (e.g. general practitioners) which was historically poor [17-19]. Raising the profile of the IR specialty among both medical professionals and the general public can potentially generate a positive flow-on effect for future trainee recruitment [20]. In addition to online resources, leadership roles within the junior committees of professional organisations remain a more traditional and effective approach to nurture aspiring individuals to become IR advocates. A few of the BSIR Trainee Committee members have demonstrated exceptional initiatives when organising the abovementioned IR events, establishing IR student societies in universities, and promoting other forms of IR education at both undergraduate and postgraduate levels. Also, one of the largest student engagement programmes 'Be inspIRed' has been taking place since 2010 during CIRSE annual meetings. It is organised by enthusiastic radiology trainees from all over Europe, who collaborate under the European Trainee Forum of CIRSE.

This study also shows that symposia are a useful way to present the specialty, provide career insights and trigger interest in a relaxed, face-to-face and interactive environment. With support from enthusiastic IRs, the BSIR and respective medical schools, these five events demonstrate high-quality engagement and positive recruitment effects on all stages of trainees. It should also be recognised, however, that not all attendees would become IRs. Indeed, some may become knowledgeable future referrers with whom stronger interdisciplinary collaborations can be formed. Nevertheless, a large pool of motivated and informed candidates is ultimately helpful to resolve the workforce shortage.

This study has several limitations. The subjects sampled are more motivated and therefore not representative of the general population of junior doctors and medical students, resulting in a selection bias. The survey is cross-sectional, and it is therefore not possible to determine the long-term effects of IR exposure on individuals' eventual career choices. Also, the answers for survey questions are based on retrospective recall so the study is inevitably affected by reporting biases.

\section{Conclusion}

Involvement with IR clinical activities is the most important contributor to an individual's positive view towards an IR career. IR-related elective modules, portfolio building and junior committee roles with professional organisations are important for the more motivated. IRs should continue investing time supervising junior doctors and medical students in clinical and nonclinical domains while advocating to increase IR representation in undergraduate curricula. High-quality symposia are effective in providing specialty and career information in extra-curricular 
settings. Actively inspiring and recruiting junior doctors and medical students at all stages are key to generate informed and motivated candidates for the future of IR.

Acknowledgement The authors thank all committee members, advisors, speakers and demonstrators who helped organise and run the symposia.

Funding This study was not supported by any funding.

\section{Compliance with Ethical Standards}

Conflict of interest The authors declare that they have no conflict of interest.

Consent for Publication For this type of study consent for publication is not required.

Ethical Approval For this type of study formal consent is not required.

Informed consent For this type of study informed consent is not required.

\section{Reference}

1. Royal College of Radiologist. Provision of Interventional Radiology Services, Second Edition. 2019. https://www.rcr.ac.uk/ system/files/publication/field_publication_files/bfcr198-provision-interventional-radiology-services-second-ed.pdf Accessed 5 May 2020.

2. Atiiga PA, Drozd M, Veettil R. Awareness, knowledge, and interest in interventional radiology among final year medical students in England. Clin Radiol. 2017;72(9):795-e7.

3. Alsafi Z, Bhrugubanda V, Ramachandran S, Alsafi A, Hamady $M$. Is it time for a specific undergraduate interventional radiology curriculum? Cardiovasc Interv Radiol. 2017;40(7):1062-9.

4. Lee AM, Lee MJ. Teaching IR to medical students: a call to action. Cardiovasc Interv Radiol. 2018;41(2):203-5.

5. de Gregorio MA, Guirola JA, Sierre S, Serrano-Casorran C, Gimeno MJ, Urbano J. Interventional radiology and Spanish medical students: a survey of knowledge and interests in preclinical and clinical courses. Cardiovasc Interv Radiol. 2018;41(10):1590-8.

6. Emin EI, Ruhomauly Z, Theodoulou I, Hanrahan JG, Staikoglou $\mathrm{N}$, Nicolaides $\mathrm{M}$, et al. Are interventional radiology and allied specialities neglected in undergraduate medical education? A systematic review. Ann Med Surg. 2019;40:22-30.

7. British Society of Interventional Radiology. UK Undergraduate curriculum for interventional radiology. 2014. https:// www.bsir.org/media/resources/UK_Undergraduate_Curriculum_for_IR_2014.pdf. Accessed 5 May 2020.
8. Cardiovascular and interventional radiology society of Europe. Interventional radiology curriculum for medical students. 2019. https://www.cirse.org/wp-content/uploads/2019/03/cirse_IRcurriculum_medical_students_2019_web-1.pdf. Accessed 5 May 2020.

9. Coupal TM, Gopee-Ramanan P, Martin J, Kaicker J, Welsh SR, Athreya S. Imagine IR symposium: an approach to increasing IR awareness and understanding among medical students. J Vasc Interv Radiol. 2014;8(25):1303-4.

10. Clements W, Goh GS, Nguyen J, Vrazas J, Rogan C, Lau G, et al. Establishing a platform for interest and education in interventional radiology amongst radiology trainees. Cardiovasc Interv Radiol. 2019;42(1):95-100.

11. Jaschke W, Bartal G, Trianni A, Belli AM. Fighting the gender gap in interventional radiology: facts and fiction relating to radiation. Cardiovasc Interv Radiol. 2018;41(8):1254-6.

12. Leong S, Keeling AN, Lee MJ. A survey of interventional radiology awareness among final-year medical students in a European country. Cardiovasc Interv Radiol. 2009;32(4):623-9.

13. Alsafi Z, Ramachandran S, Bhrugubanda V, Graham A, Alsafi A. Foundation doctors' exposure to interventional radiology in two large teaching hospitals in the United Kingdom. Arab J Interv Radiol. 2020;4(2):96-101.

14. Shaikh M, Shaygi B, Asadi H, Thanaratnam P, Pennycooke K, Mirza $\mathrm{M}$, et al. The introduction of an undergraduate interventional radiology (IR) curriculum: impact on medical student knowledge and interest in IR. Cardiovasc Interv Radiol. 2016;39(4):514-21.

15. Theodoulou I, Louca C, Sideris M, et al. A prospective study integrating a curriculum of interventional radiology in undergraduate education: a tetra-core simulation model. CVIR Endovasc. 2020;3(1):1-7.

16. Rostampour S, Hamady MS, Alsafi A. To tweet or not to tweet? A look at radiology societies' use of twitter. Cardiovasc Interv Radiol. 2020;43:1070-4.

17. Heister D, Jackson S, Doherty-Simor M, Newton I. An evaluation of trends in patient and public awareness of IR. J Vasc Interv Radiol. 2018;29(5):661-8.

18. Mok PS, Tan EY, Baerlocher MO, Athreya S. What do family physicians know about interventional radiology? A survey of family physicians at a large Canadian annual scientific assembly. J Vasc Interv Radiol. 2010;21(8):1250-4.

19. Baerlocher MO, Asch MR, Puri G, Vellahottam A, Myers A, Andrews K. Awareness of interventional radiology among patients referred to the interventional radiology department: a survey of patients in a large Canadian community hospital. J Vasc Interv Radiol. 2007;18(5):633-e1.

20. Malpani R, Chan SM, Latich I, Vatakencherry GG. An early start: the need to promote awareness about vascular and interventional radiology among premedical students. Acad Radiol. 2020. https:// doi.org/10.1016/j.acra.2020.06.042.

Publisher's Note Springer Nature remains neutral with regard to jurisdictional claims in published maps and institutional affiliations. 